Original Research

\title{
Multi-Species Probiotic Modulates Cytokine Production and the Interplay between Immune and Colon Cancer Cells
}

Meir Djaldetti ${ }^{1}$, Chiya Moshe Leibovitch ${ }^{2}$, Hanna Bessler ${ }^{1, *}$

1. Laboratory for Immunology and Hematology Research, Rabin Medical Center, Hasharon Hospital, Petah-Tiqva, the Sackler School of Medicine, Tel-Aviv University, Ramat Aviv, Israel; EMails: meird@clalit.org.il; hannab@clalit.org.il

2. Institute of Hematology, Davidoff Cancer Center, Rabin Medical Center, Petah-Tiqva, the Sackler School of Medicine, Tel-Aviv University, Ramat Aviv, Israel; E-Mail: leibovitch@clalit.org.il

* Correspondence: Hanna Bessler; E-Mail: hannab@clalit.org.il

Academic Editor: Rostyslav Bubnov

Special Issue: Gut Microbiota and Gut Health

OBM Hepatology and Gastroenterology

2020, volume 4, issue 4

doi:10.21926/obm.hg.2004053
Received: June 28, 2020

Accepted: November 10, 2020

Published: November 19, 2020

\begin{abstract}
The current study aimed to investigate the effect of a multi-species probiotic (MSP) on cytokine production by human peripheral blood mononuclear cells (PBMCs) and their immune dialogue with HT-29 colon cancer cells. PBMCs were incubated with MSP and their effect on cell proliferation and TNF $\alpha, \mathrm{IL}-1 \beta, \mathrm{IL}-2, \mathrm{IL}-6, \mathrm{IFN} \gamma, \mathrm{IL}-10$, and IL-1ra production was evaluated. The impact of MSP on the cytokine production by PBMC stimulated by HT-29 cells was detected. Not-stimulated PBMC incubated with MSP showed increased production of TNF $\alpha$, IL-1 $\beta$, IL-6, and IL-10, but no change in IL-6, IFN $\gamma$, and IL-1ra. The stimulatory effect of MSP on lipopolysaccharide (LPS)-promoted PBMC was less pronounced for TNF $\alpha, \mathrm{IL}-1 \beta$, and IFN $\gamma$, and the IL-6 production was decreased; phorbol 12-myristate 13- acetate (PMA)induced IL-2 and IFN $\gamma$ secretion was inhibited. The addition of MSP to co-cultures of PBMC and HT-29 cancer cells caused a remarkable increase in TNF $\alpha$ and IL-1 $\beta$ secretion, with no change in remaining cytokines. The multi-species probiotics modulated cytokine production
\end{abstract}

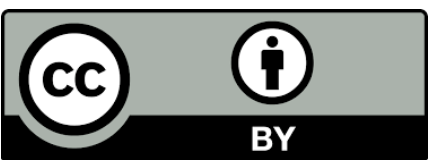

(c) 2020 by the author. This is an open access article distributed under the conditions of the Creative Commons by Attribution License, which permits unrestricted use, distribution, and reproduction in any medium or format, provided the original work is correctly cited. 
by PBMC and affected the cross-talk between PBMC and HT-29 cancer cells. We conclude that probiotics may serve as supplements to the therapeutic strategies applied for the treatment of chronic inflammatory and malignant diseases, especially colorectal cancers.

\section{Keywords}

Probiotics; cytokines; mononuclear cells; cancer cells; chronic infections; carcinoma

\section{Introduction}

The intestinal microflora, also called microbiota, settles in the gut immediately after birth and participates in different physiological functions linked to human health maintenance [1]. Alteration of microbiota constituents and activities leads to dysbiosis (dysbacteriosis) expressed by an increase in the number of pathogenic bacteria and fungi that modify the gut's immune function and trigger several complications, such as a heightened risk for the development of inflammatory bowel disease (IBD), ulcerative colitis (UC), Crohn's disease (CD), and colorectal cancer (CRC) [2-4]. The roles of various probiotic microorganisms in the normal function of the systems and their effect on the host immune response have been discussed in several reviews [5-8]. It has been shown that certain "live microorganisms", mainly from the Lactobacillus and Bifidobacterium strains, designated as probiotics, act as benefactors of human health since, in addition to their positive effect on gastrointestinal tract diseases, they express a therapeutic potential in other systems affected by dysbiosis. Treatment with probiotics may moderate the side effects in patients during stem cell transplantation [9]; alleviate symptoms of atopic dermatitis and psoriasis [10]; and rapidly improve the apical periodontitis [11]. The presence of a significant number of microorganisms in the digestive tract results in a continuous immune relationship between microbiota and the host [12-14]. The human gut has about 100 trillion microbiota of about 1000 different types. Mounting evidence has shown that the anti-inflammatory effect of the probiotics is linked to their capacities to promote macrophages for cytokine production [15]. These findings prompted researchers to investigate the therapeutic properties of probiotics on several disorders, particularly on chemotherapy-induced intestinal mucositis. It was found that mice with 5fluorouracil (5-FU) induced mucositis and diarrhea showed increased expressions of TNF $\alpha$ and IL$1 \beta$ but decreased IL-10 concentrations [16], while treatment with Lactobacillus casei Lactobacillus acidophilus and Bifidobacterium bifidum alleviated diarrhea accompanied by remarkable suppression of tumor necrosis factor(TNF)- $\alpha$, IL-1 $\beta$, interferon-gamma(IFNY), IL-6, IL-4, IL-10, and IL-17 production [17]. Similar observations have been reported in previous studies using various probiotics [18, 19]. The capacity of probiotics in general, and that of the Lactobacillus and Bifidobacteria strains, in particular, to increase the number of friendly/good bacteria and suppress intestinal inflammation by regulation of inflammatory cytokine secretion has been suggested as an adjuvant therapeutic modality against CRC [20]. Timmerman et al. [21] categorized probiotics into two groups: monostrains (i.e., containing one strain) of certain microorganisms, and multistrain (containing more than one strain) of the same microorganisms. Probiotics containing various types of microorganisms are designated as multispecies probiotics (MSP). Although probiotics may be applied as monostrains, it can be hypothesized that multi-strain and multi-species probiotics with 
different activities would be more advantageous than a single one. Wang et al. [22] noticed better results in mice with colitis treated with a combination of four microbial strains compared with those who received individual strains. Hart et al. [23] reported increased IL-10 production and decreased IFN $\gamma$ expression by dendritic cells following the effect of a probiotic mixture of eight probiotic strains. Our findings showed consistency with those in a previous study that documented a probiotic composed of six microorganisms exerted a noticeable stimulation of cytokine secretion by human PBMC [24]. The current study aimed at examining the immunomodulatory effect of a multi-species probiotic (MSP) containing eight microorganisms on cytokine production by human PBMC. Also, the effects of the probiotics on the immune cross-talk between immune cells and those from a human HT-29 colon cancer lines were assessed.

\section{Materials and Methods}

The probiotic Jarro Dophilus (Jarro Dophilus, Altman Health G.P. Or Yehuda, Israel), used in the study, is a commercial compound/preparation containing a mixture of eight complementary microbial species (MSP): Lactobacillus rhamnosus RO-11 (17.6\%), Lactobacillus casei RO-215 (13.6\%), Lactobacillus Plantarum RO-1012 (6.8\%), Lactobacillus helveticus (acidophilus) RO-52 (17.6\%), Bacillus longum BB536 (13.6\%), Bacillus breve RO-70 (6.8\%), Pediococus acidilactici RO1001 (17.4\%) and Lactococcus lactis RO-1058 (6.6\%). The probiotic was obtained as a lyophilized mixture containing a total of $8.27 \times 10^{6}$ bacteria/mg. MSP was added to peripheral blood mononuclear cells (PBMC) at the following ratios: 2.5:1, 5:1, and 10:1.

\subsection{Cell Preparation}

PBMCs were obtained from adult donors' venous blood after signing an informed consent form and agreement to use components of their blood not required for therapeutic purposes for research. The cells were separated by Lymphoprep-1077 (Axis-Shield PoC AS, Oslo, Norway) gradient centrifugation, washed twice in phosphate-buffered saline (PBS), and suspended in RPMI1640 medium (Biological Industries, Beith Haemek, Israel) containing 10\% heat-inactivated fetal bovine serum (FBS), and designated as complete medium (CM).

\subsection{Colon Cancer Cell Line}

HT-29 human colon cancer cell line was obtained from American Type Cultural Collection (Rockville, MD, USA). The cells were maintained in CM containing McCoy's 5A medium (Biological Industries Co, Beth-Haemek, Israel), supplemented with 10\% FBS, 2 mM L-glutamine, and antibiotics (penicillin, streptomycin, and nystatin (Biological Industries, Kibbutz, Beit-Haemek, 25115 , Israel). The cells were grown in T-75 culture flasks at $37{ }^{\circ} \mathrm{C}$ in a humidified atmosphere containing $5 \% \mathrm{CO}_{2}$. The viability of both PBMC and HT-19 cells was over $95 \%$. HT-29 cells were cultivated separately and were mixed with PBMC before commencing suitable experiments.

\subsection{Effect of MSP on Cytokine Production}

PBMC ( $4 \times 10^{6} / \mathrm{mL}$ of $\left.\mathrm{CM}\right), 0.5 \mathrm{~mL}$ was incubated with an equal volume of $\mathrm{CM}$ without or with 40 $\mathrm{ng} / \mathrm{mL}$ lipopolysaccharide (LPS, Escherichia coli, Sigma-Aldrich) or with $1 \mu \mathrm{g} / \mathrm{mL}$ of phorbol 12 myristate 13-acetate(PMA) and $0.5 \mu \mathrm{g} / \mathrm{mL}$ of ionomycin (Sigma Aldrich, Israel) or with $0.5 \mathrm{~mL}$ of 
HT-29 colon cancer cells $\left(4 \times 10^{5} / \mathrm{mL}\right.$ of $\left.\mathrm{CM}\right)$ suspended in appropriate CM. MSP was added at the onset of cultures at a volume of $10 \mu \mathrm{L} / \mathrm{mL}$. The ratio between MSP and PBMC was 2.5:1, 5:1, and 10:1. Control cultures contained only CM. The cultures were incubated for $24 \mathrm{~h}$ at $37{ }^{\circ} \mathrm{C}$ in a humidified atmosphere containing $5 \% \mathrm{CO}_{2}$. At the end of the incubation period, the cells were removed by centrifugation at $250 \mathrm{~g}$ for $10 \mathrm{~min}$; the supernatants were collected and kept at $-70{ }^{\circ} \mathrm{C}$ until assayed for cytokines content.

\subsection{Effect of MSP on Cell Proliferation}

The effect of MSP on PBMC and HT-29 cell proliferation was examined separately by applying XTT proliferation assay kit (Biological Industries, Beith Haemek, Israel). Overall, $0.1 \mathrm{~mL}$ aliquots of PBMC or HT-29 cells obtained after trypsinization and suspended at $10^{5} / \mathrm{mL}$ in the appropriate CM were added to each well plate $(\mathrm{N}=96)$ and incubated for $24 \mathrm{~h}$ in the absence or presence of MSP added at the onset of cultures at concentrations as indicated. At the end of the incubation period, the cells were stained according to the manufacturer's instructions. The plates were incubated for $3 \mathrm{~h}$ at $37{ }^{\circ} \mathrm{C}$ in a humidified incubator containing $5 \% \mathrm{CO}_{2}$, and the absorbance was measured at $450 \mathrm{nM}$ using an ELISA reader.

\subsection{Cytokine Content in the Supernatants}

The concentrations of some cytokines (TNF $\alpha, \mathrm{IL}-1 \beta, \mathrm{IL}-6, \mathrm{IFN} \gamma, \mathrm{IL}-10, \mathrm{IL}-1 \mathrm{ra}$, and IL-2) in the supernatants were measured using ELISA kits (Biosource International, Camarillo, CA, USA) specific for these cytokines as detailed in the manufacturer's guidelines. On the day of ELISA assay, supernatant samples were thawed and aliquots were added into ELISA plates in duplicate. The detection levels of these kits were: $15 \mathrm{pg} / \mathrm{mL}$ for $\mathrm{IL}-6$ and $30 \mathrm{pg} / \mathrm{mL}$ for the remaining cytokines.

\subsection{Statistical Analysis}

A linear mixed model with repeated measures ANOVA and the assumption of compound symmetry (CS) was used to assess the effects of MSP to PBMC ratios and cell lines on cytokine levels. The Base Statistical Analysis System(SAS) and SAS/STAT version 9.4 for Windows PC were used for this analysis. A paired t-test was used to compare the levels of cytokine produced with various concentrations of MSP and those found in control cultures (incubated without MSP). Probability values of $\mathrm{p}<0.05$ were considered significant. The results are expressed as mean $\pm \mathrm{SEM}$.

\section{Results}

No detectable levels of any of the cytokines tested could be found in supernatants that were collected from MSP incubated for $24 \mathrm{~h}$ at given concentrations of $0.5 \times 10^{8} / \mathrm{mL}, 1 \times 10^{8} / \mathrm{mL}$, or $2 \times 10^{8} / \mathrm{mL}$.

\subsection{Effect of MSP on Cell Proliferation (Figure 1)}

PBMC and HT-29 cell lines incubated for $24 \mathrm{~h}$ with MSP at the aforementioned ratios of MSP:PBMC or MSP/HT-29 showed inhibited proliferation. At PBMC ratio of 2.5:1, 5:1 and 10:1, the 
proliferation of PBMC decreased by 15\%, $(p=0.06) 39 \%(p<0.001)$ and $76 \%(p<0.001)$, whereas that of HT-29 was lowered by $49 \%(p<0.05)$ at $10: 1$ ratio only.

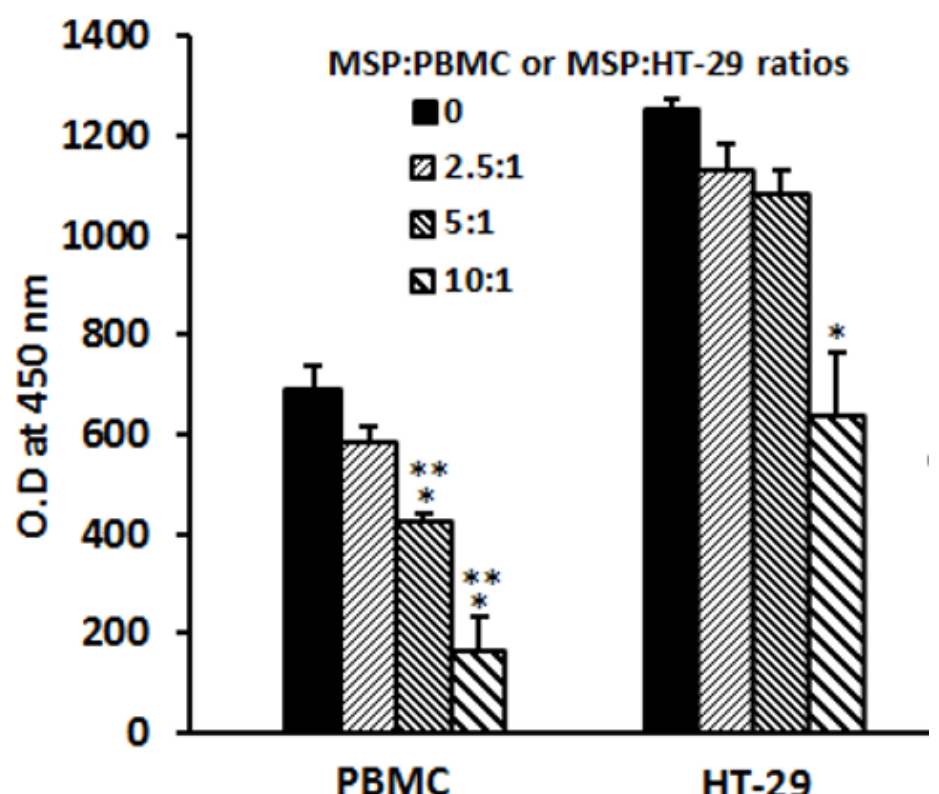

Figure 1 Effect of MSP on cell proliferation. PBMC or HT-29 cell lines were incubated for $24 \mathrm{~h}$ at $37{ }^{\circ} \mathrm{C}$ in a humidified incubator containing $5 \% \mathrm{CO}_{2}$ in the absence $(0$, shown by black lines in the illustration) or presence of MSP added at the onset of cultures at MSP: PBMC or MS: HT-29 ratios as indicated. The proliferation rate was examined applying XTT assay as described in the Materials and Methods section. At the end of the incubation period the cells were stained according to the manufacturer's instructions; absorbance was measured at $450 \mathrm{~nm}$ using an ELISA reader. Each column represents the mean of 6 experiments. Bars represent SEM. Asterisks represent statistically significant difference from cells incubated without MSP $(0) \quad\left({ }^{*} p<0.05\right.$; $\left.*_{*} * \mathrm{p}<0.001\right)$.

\subsection{Effect of MSP on Cytokine Secretion by HT-29 Cells}

Twenty-four-hour of incubation of HT-29 cells with or without MSP at the concentrations applied did not reveal detectable amounts of any cytokine in the supernatants.

\subsection{Effect of MSP on Pro-inflammatory Cytokine Secretion}

\subsubsection{Not-stimulated PBMC (Figure 2)}

Incubation of non-stimulated PBMC with MSP revealed an abundantly increased production of TNF $\alpha, I L-1 \beta(p<0.001)$, and IL-6 ( $p<0.005)$. At 2.5:1 MSP to PBMC ratio the secretion of TNF $\alpha, I L-1 \beta$, and IL- 6 was enhanced by $6.8,13.7$, and 3.2 times compared to PBMC incubated without MSP $(p<0.001)$. At higher ratios of bacteria to PBMC, the increased production of cytokines was similar. The secretion of IFN $\gamma$ was not affected $(p=0.47)$. 


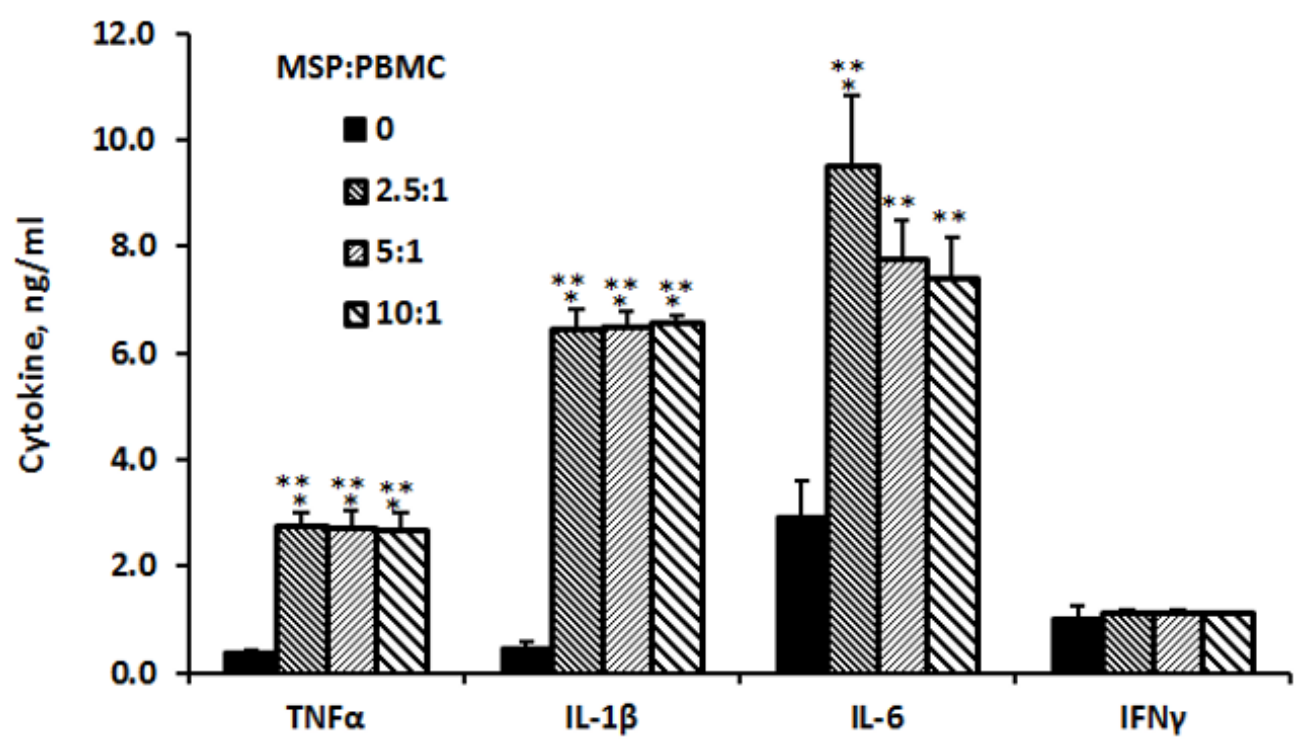

Figure 2 Effects of MSP on pro-inflammatory cytokine production (TNF $\alpha$, IL-1 $\beta$, IL-6, INFy) by non-stimulated PBMC. Not-stimulated PBMC were incubated for $24 \mathrm{~h}$ without (0) or with MSP at ratios (2.5:1-10:1) as depicted. The concentration of the cytokines in the supernatant collected following the incubation period was determined using ELISA kits. Each column represents the mean results of four different samples. Bars represent SEM. * represents statistically significant difference from PBMC incubated without MSP (0) $\left(* * p<0.01 ; *_{*}^{*} p<0.001\right)$.

\subsubsection{Lipopolysaccharides (LPS)-induced Cytokine Production (Figure 3)}

The production of TNF $\alpha, I L-1 \beta$, and IFN $\gamma$ by LPS-stimulated PBMC showed a notable increase following the incubation with MSP $(p<0.01, p<0.005$, and $p<0.02$, respectively), whereas relative production of IL-6 was significantly reduced $(p<0.001)$. At MSP to PBMC ratio of $2.5: 1$, the production of TNF $\alpha, I L-1 \beta$, and IFN $\gamma$ was stimulated by $53 \%, 25 \%$, and $11 \%$, respectively $(p=0.02$, $p=0.023$, and $p=0.005$, respectively). Similar increased production of these cytokines by LPSstimulated PBMC was observed at higher ratios of MSP: PBMC. However, the production of IL- 6 by LPS stimulated PBMC was inhibited by 50\%, 57\%, and 45\% $(p<0.001)$ at MSP: PBMC ratios of 2.5:1, $5: 1$, and $10: 1$, respectively. 


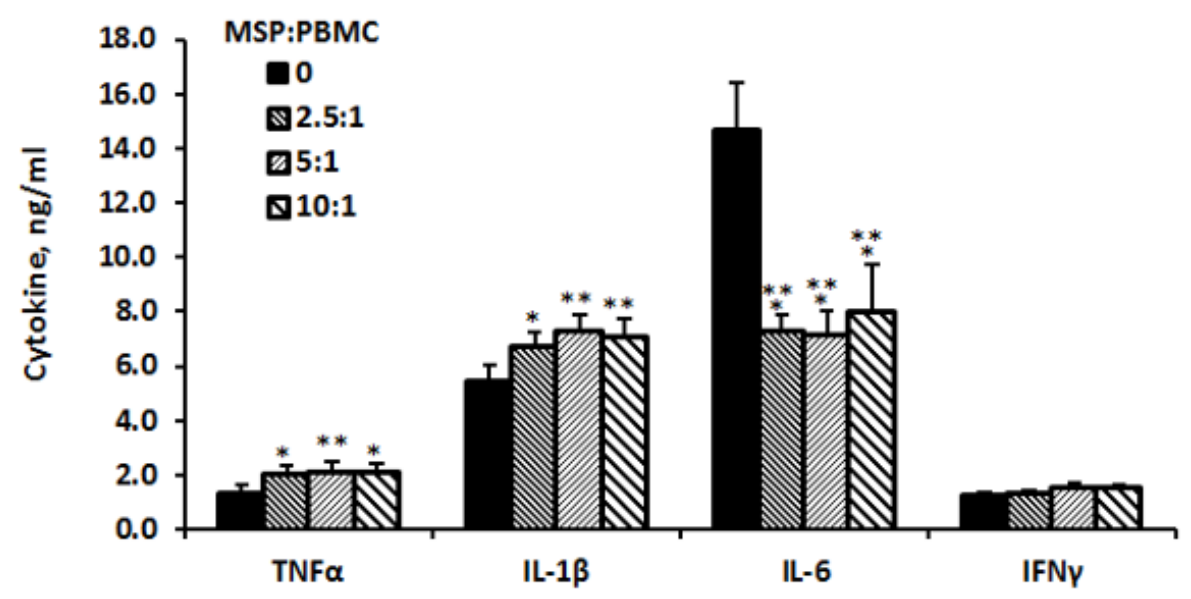

Figure 3 Effect of MSP on pro-inflammatory cytokine (TNF $\alpha$, IL-1 $\beta$, IL-6, INFy) production by LPS-stimulated PBMC. PBMC were incubated for $24 \mathrm{~h}$ in the presence of LPS (40ng/mL) without (0) or with MSP at MSP: PBMC ratios as shown in the above figure. After the incubation period, supernatants were collected and the concentration of the cytokines was determined using ELISA kits. Each column represents the mean results of four different samples. Bars represent SEM. Asterisks represent statistically significant difference from PBMC incubated without MSP (0) $\left({ }^{*} p<0.01 ; *^{*} p<0.001\right)$.

\subsubsection{HT-29-induced Cytokine Production (Figure 4)}

The secretion of TNF $\alpha$ and IL- 6 by PBMC induced by HT-29 colon cancer cells was not affected following incubation with MSP at the ratios indicated ( $p>0.1)$, whereas that of IL-1 $\beta$ and IFN $\gamma$ was slightly reduced $(p<0.005)$. At MSP to PBMC ratio of $5: 1$, the secretion of IL-1 $\beta$ and IFN $\gamma$ induced by HT-29 cells was inhibited by $16 \%(p<0.03)$ and $26 \%(p<0.01)$, respectively.

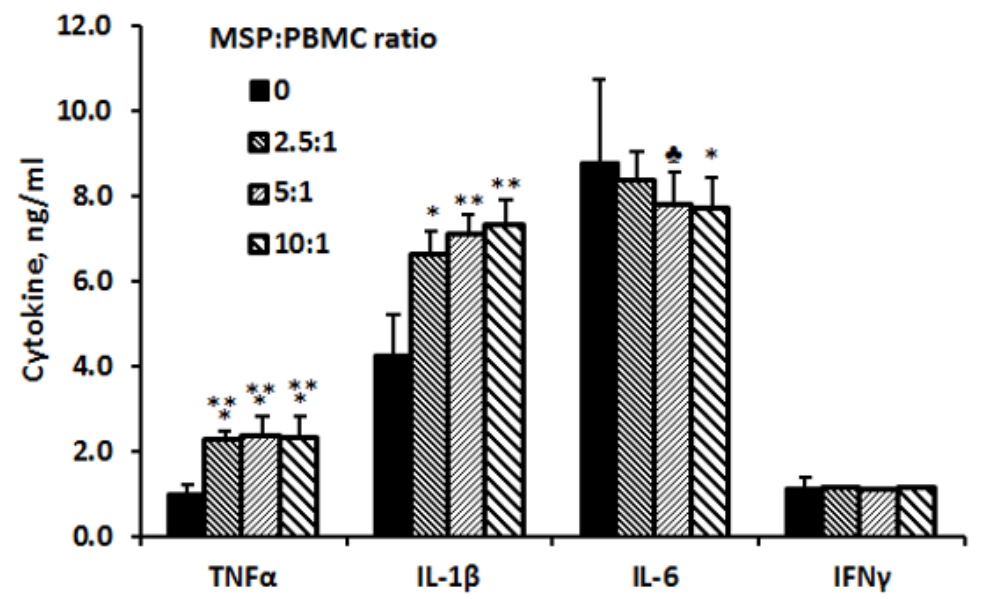

Figure 4 Effect of MSP on pro-inflammatory cytokine production by HT-29-stimulated PBMC. PBMCs were incubated for $24 \mathrm{~h}$ in the presence of HT-29 colon cancer cells without (0) or with MSP at MSP: PBMC ratios as indicated. Following the incubation period, supernatants were collected and the concentrations of the cytokines were measured using ELISA kits. Each column represents the mean results of four different samples. Bars represent SEM. Asterisks represent statistically significant difference from PBMC incubated without MSP $(0)\left({ }^{*} p<0.05 ;{ }^{*} p<0.01 ;{ }^{*}{ }^{*} p<0.001 ;{ }_{p}=0.06\right)$. 


\subsection{Effect of MSP on PMA-induced IL-2 and IFNY Secretion (Figure 5)}

The secretion of IL-2 and IFNy by PMA- stimulated PBMC was inhibited in a dose-dependent manner ( $p<0.001$ for IL-2 and $p=0.0018$ for IFN $\gamma$ ). At MSP:PBMC ratios of 2.5:1, 5:1, and 10:1 the production of IL-2 was inhibited by $23 \%, 26 \%(p<0.01)$ and $66 \%(p<0.001)$, respectively, whereas that of IFN $\gamma$ was reduced by $10 \%(p=0.4), 21 \%(p<0.05)$ and $41 \%(p=0.0018)$, respectively.

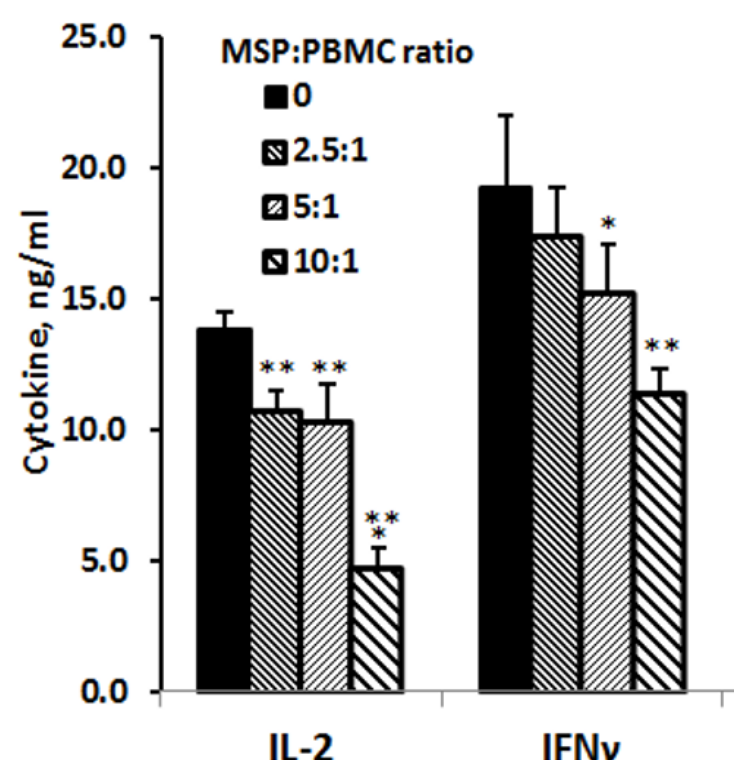

Figure 5 Effect of MSP on IL-2 and IFNy secretion by PMA/ionomycin-stimulated PBMC. PBMC were incubated for $24 \mathrm{~h}$ with $\mathrm{PMA} /$ ionomycin $(1 \mu \mathrm{g}$ or $0.5 \mu \mathrm{g} / \mathrm{mL})$ without $(0)$ or in the presence of MSP at other 3 ratios $(2.5: 1 ; 5: 1 ; 10: 1)$ of MSP: PBMC as indicated. Following the incubation period, supernatants were collected and the concentration of the cytokines was evaluated using ELISA kits. Each column represents the mean results of four different samples. Bars represent SEM. Asterisks represent statistically significant difference from PBMC incubated without MSP (0) $\left({ }^{*} p<0.05 ;{ }^{* *} p<0.01\right.$; $\left.*_{*} * \mathrm{p}<0.001\right)$.

\subsection{Effect of MSP on Anti-inflammatory Cytokine Secretion (Figure 6)}

The secretion of IL-10 by not-stimulated PBMC was significantly increased $(p=0.001)$ and was x8.3, x6.8, and x6.5 higher at MSP: PBMC ratios of 2.5:1, 5:1, and 10:1, respectively. IL-10 production by LPS stimulated PBMC was slightly reduced $(p<0.05)$ and was lower by $29 \%$ at a ratio of $10: 1$ only $(p=0.038)$ and was statistically nonsignificant, whereas that induced by HT-29 cells was not affected $(p=0.55)$.

The production of IL-1ra by not-stimulated, LPS stimulated PBMC or that induced by HT-29 cells was not affected, following incubation with MSP at the ratios tested. 


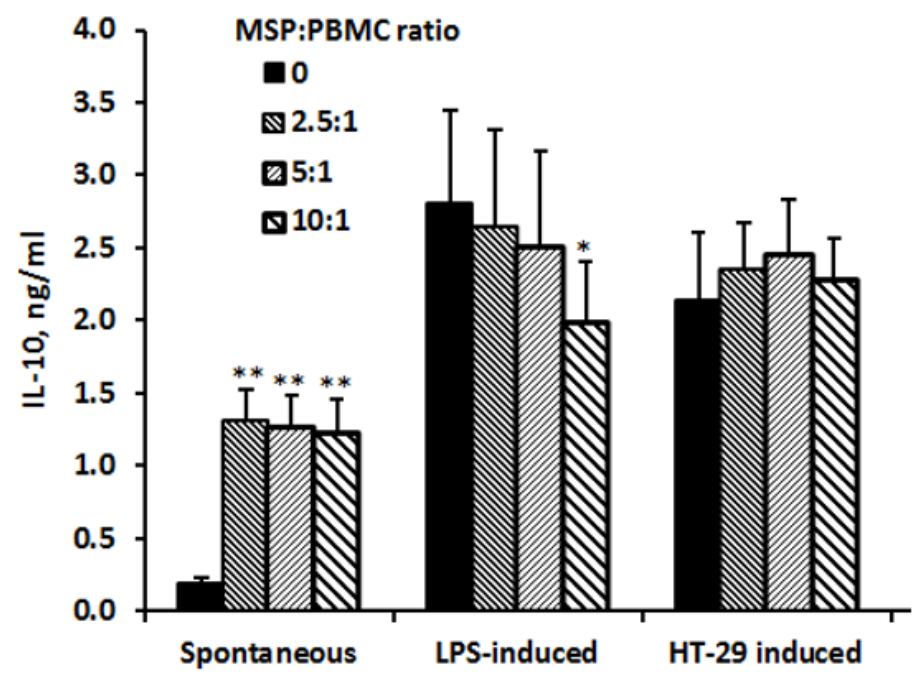

Figure 6 Effect of MSP on IL-10 secretion by not-stimulated, LPS or HT-29 stimulated PBMC. Not-stimulated PBMC or cells stimulated with LPS $(40 \mathrm{ng} / \mathrm{mL})$ or HT-29 colon cancer cells were incubated for $24 \mathrm{~h}$ without (0) or with MSP at ratios of MSP: PBMC as shown in the figure above. After the incubation period, the supernatants were collected, and the concentration of IL-10 was tested using ELISA kits.

\section{Discussion}

The immune interaction between microbiota and the intestinal mucosa is well documented [14]. Microbiota regulates various activities of the intestinal dendritic cells and macrophages, including their ability for cytokine production [25]. According to Matsuzaki et al. [26], the microbiota colonizes Peyer's patches and promotes the capacity of dendritic cells for phagocytosis. The phagocytized microflora release components to activate the ability of the immune cells to generate cytokines. The production of the anti-inflammatory cytokine IL-10 is of great importance since it has been shown that IL-10 deficiency in humans and mice increases the predisposition for ulcerative colitis and irritable bowel syndrome [27]. In the present study, not-stimulated PBMC incubated with MSP at various ratios enhanced IL-10 production. Similar results were obtained for the remaining cytokines hitherto examined, except for the expression of IL-2, IFN $\gamma$, and IL-1ra that remained unaffected. Compellingly, when the same experiments were carried out with LPSstimulated cells, the increased production of TNF $\alpha$, IL-1 13 , and IFN $\gamma$ was less conspicuous; the secretion of the pro-inflammatory cytokines IL- 6 and that of PMA-stimulated IL-2 and IFNY was reduced. In this setup, the generation of IL-1ra and IL-10 remained unchanged. The mode of PBMC activity related to their stimulation is important since one would expect that stimulated cells are more active in cytokine production than not-stimulated ones. Diverse cytokine secretion by PBMC in relation to MSP concentrations has also been reported in several studies. D'Hellencourt et al. [28] unraveled that the effect of pentoxifylline on cytokine production depended on the cellular environment and methods of cell activation. Inturri et al. [29] observed that not-stimulated human PBMC incubated with Bifidobacterium longum exopolysaccharides produced more IL-10 and IL-6 than ConA-stimulated cells; this finding was corroborated in our research. It is plausible that cells stimulated by LPS/ConA reach their maximal activity for cytokine production, rendering further stimulation by MSP to be less prominent. 
The question arises about the better method to administer probiotics, a single strain or as a combination of several bacterial brands as the one illustrated in our research. The effect of individual probiotic bacterial strains on the immune system has been well established. Matsuzaki et al.[30] reported the capability of Lactobacillus casei to stimulate host immune cells to produce several cytokines, including TNF $\alpha$. Administration of Lactobacillus casei to mice inhibited the inflammatory activity of 1,2-dimethylhydrazine (DMH) by maintaining the levels of IFN $\gamma$, TNF $\alpha$, and IL-10 [31]. In an in vitro model, Lactobacillus casei constrained the activity of polyinosinic polycytidylic acid expressed by inhibited production of the pro-inflammatory cytokines TNF- $\alpha$ and IFN $\gamma$ by human PBMC [32]. The cytokine production in the present study under the effect of a probiotic containing eight microbial species is similar to those reported by Dong et al. [33] who observed that Lactobacillus casei, a monostrain probiotic, incubated with non-stimulated monocytes showed increased production of IL- $\beta, \mathrm{IL}-10, \mathrm{IL}-6, \mathrm{IL}-12$, and TNF $\alpha$. In the current study, in LPS-stimulated cells, the secretion of IL-1 $\beta$ was increased, while that of IL-10 and IL- 6 was inhibited and TNF $\alpha$ remained unchanged. The stimulatory effect of various species of Lactobacillus casei on anti-inflammatory cytokine expression and particularly on that of IL-10 has been documented in studies on animals infected with a variety of pathogenic microorganisms [34, 35]. The remaining components of the probiotic compound investigated in the present study are also known as active immunomodulators. Thus, Lactobacillus rhamnosus at its different strains and soluble mediators has been shown to up-regulate secretion of IL-8, IL-6, IL-12p70, and TNF $\alpha$ [36] by human macrophages; boost the capacity of dendritic cells for IL-2 and IFN- $\gamma$ production [37], and inhibit the secretion of IL-8 by intestinal epithelial cells [38]. Pagnini et al. [39] demonstrated that Lactobacillus rhamnosus restricts the expression of TNF $\alpha$ and IL-17 by colonic cells in patients with ulcerative colitis. Lactobacillus plantarum exerted an inhibitory effect on IL-8 and TNF $\alpha$ levels when added to cultures of porcine enterocytes [40] and human colon adenocarcinoma cells (Caco2) [41]. As for the immunomodulatory properties of the remaining bacterial species included in the studied probiotic blend, it has been reported that Lactobacillus lactis incubated with intestinal mucosa of patients with inflammatory bowel disease increased IL-10 secretion and decreased the expression of the pro-inflammatory cytokines: TNF $\alpha$ and IL-23 [42]. Intragastric administration of IL-10 secreted by Lactobacillus lactis improved the course of murine colitis by $50 \%$ [43]. Pediococcus acidilactici was shown to trigger the production of IL-10 $\operatorname{Tr} 1$ cells in an animal model of multiple sclerosis [44] and inhibit the secretion of the pro-inflammatory cytokines IL-6 and IFN $\gamma$ in pigs [45].

It may be assumed that multi-strain and multispecies probiotics possessing similar biological properties may be more immune-effective compared to a single-species probiotic. A previous study carried out at a laboratory setup identical to the one hereby presented, but using a probiotic containing six bacterial species revealed similar stimulatory effects on the production of the proinflammatory cytokines TNF $\alpha$ and IL- 6 by non-stimulated PBMC, while the secretion of IL-1 $\beta$ in response to MSP in the present study was twice higher. The production of pro-inflammatory cytokines by LPS stimulated PBMC in response to the two probiotic preparations did not differ significantly [24]. However, it has been stated that multi-strains and multi-species probiotics are advantageous against pathogens compared to single-strains and single-species probiotics [21, 4648]. It is suggested to carry-on further studies in order to clarify the topic [49].

The capacity of probiotics to modulate carcinogenesis has drawn wide attention. In the present study, treatment of HT-29 colon cancer cells with MSP resulted in marked suppression of cell 
proliferation, a finding similar to that reported for other types of cancer cells treated with Lactococcus lactis [50]. Arguably, MSO halts the progress of cell mitosis at the G1 phase by generating G1 dependent kinases that inhibit the activity of Retinoblastoma-protein (pRB) responsible for the progress of the cell cycle [51]. Although in vitro models may not always be fully representative of the intricate processes occurring in vivo, the MSP-reduced cell proliferation observed in the study may explain one of the ways how probiotics may attenuate the progress of carcinogenesis. Since dysbiosis frequently accompanies the close relationship between chronic inflammation and cancer development, particularly in the gastrointestinal tract, probiotics may likely have a beneficial antitumor activity by regulation of the intestinal microflora [1]. One of the mechanisms by which probiotics could slowdown cancer development is the inhibition of intestinal inflammation by the release of anti-inflammatory cytokines produced by immune cells [31, 52]. Zaharuddin et al. [53] observed a significant decrease in the level of pro-inflammatory cytokines: TNF $\alpha, \mathrm{IL}-6, \mathrm{IL}-12, \mathrm{IL}-17$, and IL-22 in postsurgical colorectal patients treated for six months with Lactobacillus and Bifidobacteria strains, compared to controls. Other types of malignancy respond favorably to probiotics. Administration of Lactobacillus casei fermented milk to mice with breast cancer led to a reduction of tumor growth and fewer metastases, as well as a decrease in the number of tumor-associated macrophages, compared to controls [54]. In our study, when PBMC was co-cultured with HT-29 cells in the presence of MSP there was increased production of TNF $\alpha$ and IL-1 $\beta$ and a slight decrease in IL- 6 observed the higher MSP: PMBC ratios. The rest of the cytokines examined in the study were not affected. Enhanced production of TNF $\alpha$ and IL-1 $\beta$ by PBMC incubated with HT-29 or RKO colon cancer cells was observed in a study using a probiotic containing six microbial strains [24].

\section{Conclusion}

Overall, it may be hypothesized that probiotics, either as a single- or as multi-species preparations can modulate immune cells properties. Consequently, they may serve as significant supplements to the therapeutic strategies applied for the treatment of colorectal cancer as well as other malignancies. This study may help the professionals and researchers to evolve better therapeutic interventions in deadly colorectal cancers and check them at the onset stage itself.

\section{Acknowledgments}

We wish to thank Ms. Tzippy Shochat, M.Sc., Statistical Consultant, Rabin Medical Center, Beilinson Hospital, for her profound support in performing the statistical computations.

\section{Author Contributions}

$M D$ and $\mathrm{HB}$ conceived the idea and the methodology. $\mathrm{HB}$ and CML performed the laboratory studies. MD - the writing of the original draft. All authors participated in the interpretation and significance of the results.

\section{Competing Interests}

The authors have declared that no competing interests exist. 


\section{References}

1. Tomasello G, Tralongo P, Damiani P, Emanuele S, Di Trapani B, Zeenny MN, et al. Dismicrobism in inflammatory bowel disease and colorectal cancer: Changes in response of colocytes. World J Gastroenterol. 2014; 20: 18121-18130.

2. Ghouri YA, Richards DM, Rahimi EF, Krill JT, Jelinek KA, DuPont AW. Systematic review of randomized controlled trials of probiotics, prebiotics, and synbiotics in inflammatory bowel disease. Clin Exp Gastroenterol. 2014; 7: 473-487.

3. Shi N, Li N, Duan XW, Niu HT. Interaction between the gut microbiome and mucosal immune system. Mil Med Res. 2017; 4: 14.

4. Pushpanathan P, Mathew GS, Selvarajan S, Seshadri KG, Srikanth P. Gut microbiota and its mysteries. Indian J Med Microbiol. 2019; 37: 268-277.

5. Parker EC, Gossard CM, Dolan KE, Finley HJ, Burns CM, Gasta MG, et al. Probiotics and disease: A comprehensive summary-part 2, commercially produced cultured and fermented foods commonly available in the United States. Integr Med. 2016; 15: 22-30.

6. Dolan KE, Finley HJ, Burns CM, Gasta MG, Gossard CM, Parker EC, et al. Probiotics and disease: A comprehensive summary-part 1, mental and neurological health. Integr Med. 2016; 15: 4658.

7. Dolan KE, Pizano JM, Gossard CM, Williamson CB, Burns CM, Gasta MG, et al. Probiotics and disease: A comprehensive summary-part 6, skin health. Integr Med. 2017; 16: 32-41.

8. Pizano JM, Williamson CB, Dolan KE, Gossard CM, Burns CM, Gasta MG, et al. Probiotics and disease: A comprehensive summary-part 7, immune disorders. Integr Med. 2017; 16: 46-57.

9. Andermann TM, Rezvani A, Bhatt AS. Microbiota manipulation with prebiotics and probiotics in patients undergoing stem cell transplantation. Curr Hematol Malig Rep. 2016; 11: 19-28.

10. Holowacz S, Guinobert I, Guilbot A, Hidalgo S, Bisson JF. A mixture of five bacterial strains attenuates skin inflammation in mice. Antiinflamm Antiallergy Agents Med Chem. 2018; 17: 125-137.

11. Cosme-Silva L, Dal-Fabbro R, Cintra LT, Dos Santos VR, Duque C, Ervolino E, et al. Systemic administration of probiotics reduces the severity of apical periodontitis. Int Endod J. 2019; 52: 1738-1749.

12. Williams NT. Probiotics. Am J Health Syst Pharm. 2010; 67: 449-458.

13. Ichikawa $M$, Sujino $T$, Kanai $T$. The relationship between gut microbiome, immune system, and cancer. Gan To Kagaku Ryoho. 2019; 46: 1807-1813.

14. Zhang CX, Wang HY, Chen TX. Interactions between intestinal microflora/probiotics and the immune system. Biomed Res Int. 2019; 2019: 6764919.

15. Kaji R, Kiyoshima-Shibata J, Tsujibe S, Nanno M, Shida K. Short communication: Probiotic induction of interleukin-10 and interleukin-12 production by macrophages is modulated by co-stimulation with microbial components. J Dairy Sci. 2018; 101: 2838-2841.

16. Justino PF, Melo LF, Nogueira AF, Morais CM, Mende s WO, Franco AX, et al. Regulatory role of Lactobacillus acidophilus on inflammation and gastric dysmotility in intestinal mucositis induced by 5-fluorouracil in mice. Cancer Chemother Pharmacol. 2015; 75: 559-567 
17. Huang L, Chiang Chiau JS, Cheng ML, Chan WT, Jiang CB, Chang SW, et al. SCID/NOD mice model for 5-FU induced intestinal mucositis: Safety and effects of probiotics as therapy. Pediatr Neonatol. 2019; 60: 252-260.

18. Yeung $\mathrm{CY}$, Chan $\mathrm{WT}$, Jiang $\mathrm{CB}$, Cheng $\mathrm{ML}$, Liu $\mathrm{CY}$, Chang SW, et al. Amelioration of chemotherapy-induced intestinal mucositis by orally administered probiotics in a mouse model. PLoS One. 2015; 10: e0138746.

19. Mi H, Dong Y, Zhang B, Wang HN, Chung CK, Ping G, et al. Bifidobacterium infantis ameliorates chemotherapy-induced intestinal mucositis via regulating $\mathrm{T}$ cell immunity in colorectal cancer rats. Cell Physiol Biochem. 2017; 42: 2330-2341.

20. Geier MS, Butler RN, Howarth GS. Probiotics, prebiotics and synbiotics: $A$ role in chemoprevention for colorectal cancer? Cancer Biol Ther. 2006; 5: 1265-1269.

21. Timmerman HM, Koning CJ, Mulder L, Rombouts FM, Beynen AC. Monostrain, multistrain and multispecies probiotics-A comparison of functionality and efficacy. Int J Food Microbiol. 2004; 96: 219-233.

22. Wang S, Yao BQ, Gao H, Zang JJ, Tao SY, Zhang S, et al. Combined supplementation of Lactobacillus fermentum and Pediococcus acidilactici promoted growth performance, alleviated inflammation, and modulated intestinal microbiota in weaned pigs. BMC Vet Res. 2019; 15: 239.

23. Hart AL, Lammers K, Brigidi P, Vitali B, Rizzello F, Gionchetti P, et al. Modulation of human dendritic cell phenotype and function by probiotic bacteria. Gut. 2004; 53: 1602-1609.

24. Djaldetti $M$, Bessler $H$. Probiotic strains modulate cytokine production and the immune interplay between human peripheral blood mononuclear cells and colon cancer cells. FEMS Microbiol Let. 2017; 364: 1-5.

25. Scott NA, Mann ER. Regulation of mononuclear phagocyte function by the microbiota at mucosal sites. Immunology. 2020; 159: 26-38.

26. Matsuzaki T, Takagi A, Ikemura H, Matsuguchi T, Yokokura T. Intestinal microflora: Probiotics and autoimmunity. J Nutr. 2007; 137: 798S-802S.

27. Kotlarz D, Beier R, Murugan D, Diestelhorst J, Jensen O, Boztug K, et al. Loss of interleukin-10 signaling and infantile inflammatory bowel disease: Implications for diagnosis and therapy. Gastroenterology. 2012; 143: 347-355.

28. D'Hellencourt CL, Diaw L, Cornillet P. Differential regulation of TNF alpha, IL-1 beta, IL-6, IL-8, TNF beta, and IL-10 by pentoxifylline. Int J Immunopharmacol. 1996; 18: 739-748.

29. Inturri R, Mangano K, Santagati M, Intrieri M, Di Marco R, Blandino G, et al. Immunomodulatory effects of bifidobacterium longum w11 produced exopolysaccharide on cytokine production. Curr Pharm Biotechnol. 2017; 18: 883-889.

30. Matsuzaki T, Takagi A, Ikemura H, Matsuguchi T, Yokokura T. Antitumor activity and action mechanisms of Lactobacillus casei through the regulation of immune responses. Biofactors. 2004; 22: 63-66.

31. Casas-Solís J, Huizar-López MD, Irecta-Nájera CA, Pita-López ML, Santerre A. Immunomodulatory effect of Lactobacillus casei in a murine model of colon carcinogenesis. Probiotics Antimicrob Proteins. 2020; 12: 1012-1024.

32. Vintiñi E, Medina M. Non-viable Lactobacillus casei beneficially modulates poly I: C imune response in co-cultures of Human cells. Iran J Immunol. 2017; 14: 325-339. 
33. Dong H, Rowland I, Tuohy KM, Thomas LV, Yaqoob P. Selective effects of Lactobacillus casei shirota on $\mathrm{T}$ cell activation, natural killer cell activity and cytokine production. Clin Exp Immunol. 2010; 161: 378-388.

34. Souza RF, Rault L, Seyffert N, Azevedo V, Le Loir Y, S Even. Lactobacillus casei BL23 modulates the innate immune response in Staphylococcus aureus-stimulated bovine mammary epithelial cells. Benef Microbes. 2018; 9: 985-995.

35. Fayyaz I, Zahoor MA, Shahid M, Rasool MH, Nawaz Z. Effect of Lactobacillus casei on serum interleukins following enteropathogenic E.coli infection in experimental rabbits. Pak J Pharm Sci. 2018; 31: 2131-2136.

36. Rocha-Ramírez LM, Pérez-Solano RA, Castañón-Alonso SL, Moreno-Guerrero SS, RamírezPacheco A, García-Garibay M, et al. Probiotic Lactobacillus strains stimulate the inflammatory response and activate Human macrophages. J Immunol Res. 2017; 2017: 4607491.

37. Ludwig IS, Broere F, Manurung S, Lambers TT, van der Zee R, van Eden W. Lactobacillus rhamnosus GG-derived soluble mediators modulate adaptive immune cells. Front Immunol. 2018; 9: 1546.

38. Jeffrey MP, Strap JL, Jones-Taggart H, Green-Johnson JM. Suppression of intestinal epithelial cell chemokine production by Lactobacillus rhamnosus R0011 and Lactobacillus helveticus R0389 Is mediated by secreted bioactive molecules. Front Immunol. 2018; 9: 2639.

39. Pagnini C, Corleto VD, Martorelli M, Lanini C, D'Ambra G, Di Giulio E, et al. Mucosal adhesion and anti-inflammatory effects of Lactobacillus rhamnosus GG in the human colonic mucosa: $A$ proof-of-concept study. World J Gastroenterol. 2018; 24: 4652-4662.

40. Paszti-Gere E, Szeker K, Csibrik-Nemeth E, Csizinszky R, Marosi A, Palocz O, et al. Metabolites of Lactobacillus plantarum 2142 prevent oxidative stress-induced overexpression of proinflammatory cytokines in IPEC-J2 cell line. Inflammation. 2012; 35: 1487-1499.

41. Jiang M, Zhang F, Wan C, Xiong YH, Shah NP, Wei H, et al. Evaluation of probiotic properties of Lactobacillus plantarum WLPL04 isolated from human breast milk. J Dairy Sci. 2016; 99: 17361746.

42. Simčič S, Berlec A, Stopinšek S, Štrukelj B, Orel R. Engineered and wild-type L. lactis promote anti-inflammatory cytokine signalling in inflammatory bowel disease patient's mucosa. World J Microbiol Biotechnol. 2019; 35: 45.

43. Steidler L, Hans W, Schotte L, Neirynck S, Obermeier F, Falk W, et al. Treatment of murine colitis by Lactococcus lactis secreting interleukin-10. Science. 2000; 289: 1352-1355.

44. Takata K, Kinoshita M, Okuno T, Moriya M, Kohda T, Honorat JA, et al. The lactic acid bacterium Pediococcus acidilactici suppresses autoimmune encephalomyelitis by inducing IL10-producing regulatory T cells. PLoS One. 2011; 6: e27644.

45. Wang Y, Xie Q, Zhang Y, Ma W, Ning K, Xiang JY, et al. Combination of probiotics with different functions alleviate DSS-induced colitis by regulating intestinal microbiota, IL-10, and barrier function. Appl Microbiol Biotechnol. 2019; 104: 335-349.

46. Chapman CM, Gibson GR, Rowland I. Health benefits of probiotics: Are mixtures more effective than single strains? Eur J Nutr. 2011; 50: 1-17.

47. Chapman CM, Gibson GR, Rowland I. In vitro evaluation of single- and multi-strain probiotics: Inter-species inhibition between probiotic strains, and inhibition of pathogens. Anaerobe. 2012; 18: 405-413. 
48. Chapman CM, Gibson GR, Todd S, Rowland I. Comparative in vitro inhibition of urinary tract pathogens by single- and multi-strain probiotics. Eur J Nutr. 2013; 52: 1669-1677.

49. Ouwehand AC, Invernici MM, Furlaneto FA, Messora MR. Effectiveness of multistrain versus single-strain orobiotics: Current status and recommendations for the future. J Clin Gastroenterol. 2018; 52: S35-S40.

50. Han KJ, Lee NK, Park H, Pai k HD. Anticancer and anti-Inflammatory activity of probiotic Lactococcus lactis NK34. J Microbiol Biotechnol. 2015; 25: 1697-1701.

51. Gamallat Y, Meyiah A, Kuugbee ED, Hago AM, Chiwala G, Awadasseid A, et al. Lactobacillus rhamnosus induced epithelial cell apoptosis, ameliorates inflammation and prevents colon cancer development in an animal model. Biomed Pharmacother. 2016; 83 :536-541.

52. Duronio RJ, Xiong Y. Signaling pathways that control cell proliferation. Cold Spring Harb Perspect Biol. 2013; 5: a008904.

53. Zaharuddin L, Mokhtar NM, Muhammad Nawawi KN, Raja Ali RA. A randomized double-blind placebo-controlled trial of probiotics in post-surgical colorectal cancer. BMC Gastroenterol. 2019; 19: 131.

54. Aragón F, Carino S, Perdigón G, de Moreno de LeBlanc A. Inhibition of growth and metastasis of breast cancer in mice by milk fermented with Lactobacillus casei CRL 431. J Immunother. 2015; 38: 185-196.

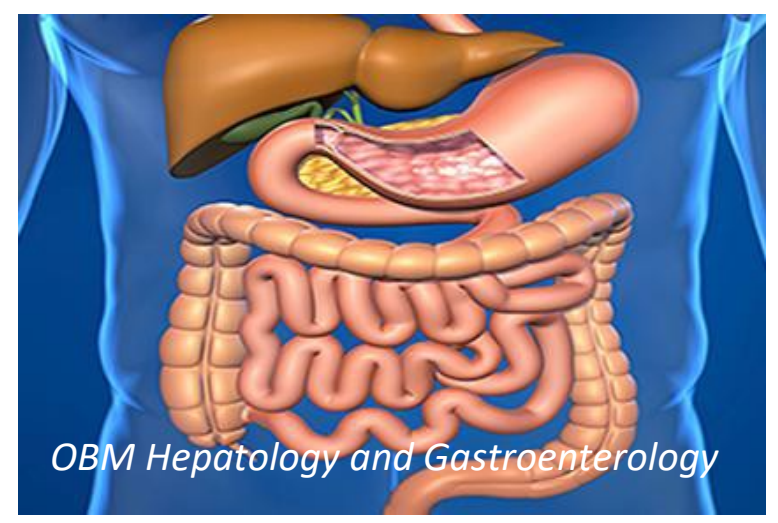

Enjoy OBM Hepatology and Gastroenterology by:

1. Submitting a manuscript

2. Joining in volunteer reviewer bank

3. Joining Editorial Board

4. Guest editing a special issue

For more details, please visit: http://www.lidsen.com/journals/hg 